\title{
INTERNASIONALISASI BAHASA INDONESIA DAN INTERNALISASI BUDAYA INDONESIA MELALUI BAHASA INDONESIA BAGI PENUTUR ASING (BIPA)
}

\author{
Dya Fatkhiyatur Rohimah \\ Universitas Negeri Malang \\ Email: dyafr@yahoo.com
}

\begin{abstract}
Language is the key to civilization, through language also communication will run well. The importance of language has become a necessity, as well as Indonesian language. In this fast-paced era, where technology is rapidly expanding and rapidly Indonesia is urgently needed to show its existence on the world scene. To do this, there are many methods that can be taken. For example through language and culture. The government has also issued a regulation on this matter. This regulation is contained in Law No. 24 of 2009 on Flags, Languages, and Emblems of State and National Anthem. That the government is committed to internationalizing Indonesian. The current real step in the effort is through BIPA (Bahasa Indonesia Bagi Penutur Asing). Where learners not only learn Indonesian language but also Indonesian culture. With the existence of BIPA is expected the language and culture of Indonesia will become more known by the world, and can parallel with other countries that have been recognized internationally.
\end{abstract}

Keywords : Language, Culture, BIPA

\section{A. Pendahuluan}

Bangsa yang besar adalah bangsa yang tidak melupakan sejarah bangsanya. Dan apabila kita tengok ke belakang pada peristiwa Sumpah Pemuda terdapat poin yang berkaitan dengan bahasa yaitu "kami putra dan putri Indonesia menjunjung bahasa persatuan bahasa Indonesia”. Maka sangat jelas bahwa bangsa Indonesia bersumpah dengan tekad yang kuat menjaga tumpah darah tanah air Indonesia dengan bahasa Indonesia selaku bahasa persatuan. Dan kini setelah hampir 90 tahun sejak diikrarkann ya Sumpah Pemuda tantangan yang dihadapi generasi muda Indonesia sekarang tentu jauh lebih berat. Kuatnya arus globalisasi menjadi salah satu penyebab gampangnya budaya dari luar merasuk ke Indonesia. Sebagai generasi penerus maka sudah menjadi kewajiban seluruh warga Indonesia khususnya pemuda-pemudi untuk mempertahankan keutuhan bangsa sekaligus Negara Indonesia.

Pemerintah pun juga sudah mengeluarkan peraturan mengenai ini, tujuannya tidak lain adalah untuk mempertahankan dan mengembangkan bahasa Indonesia agar bisa setara dengan bahasa dari Negara lain yang sudah diakui oleh dunia. Peraturan ini 
termaktub dalam Undang-Undang Nomor 24 Tahun 2009 mengenai Bendera, Bahasa, dan Lambang Negara serta Lagu Kebangsaan. Di mana pada pasal 44 ayat 1 dijelaskan bahwa pemerintah meningkatkan fungsi Bahasa Indonesia sebagai bahasa internasional secara bertahap, sistematis, dan berkelanjutan.

Pada saat ini, bahasa Indonesia telah memegang peran yang cukup besar di tingkat internasional seperti fakta bahwa bahasa Indonesia dipelajari oleh lebih dari 45 negara di dunia, selain itu di Vietnam dijadikan bahasa resmi ke-2 yang disejajarkan dengan bahasa Inggris. Bahkan di Australia bahasa Indonesia merupakan bahasa popular ke-4 dan diajarkan di lebih dari dari 500 sekolah serta menjadi mata pelajaran wajib. Sedangkan di Eropa sendiri, bahasa Indonesia juga menjelma sebagai bahasa Asia yang paling diminati ${ }^{1}$. Bahasa sebagai identitas bangsa maka pembelajaran bahasa Indonesia adalah dimensi penting yang perlu diajarkan dalam menguatkan rasa cinta generasi muda kepada bahasa dan budaya Indonesia yang unik dan beragam. Akan tetapi, pembelajaran bahasa Indonesia sekarang pun tidak hanya diberikan kepada penutur aslinya namun juga mulai merambah ke dunia internasional. $^{2}$

Ada berbagai hal yang bisa dilakukan dalam upaya menginternasionalisasi bahasa Indonesia, salah satunya yaitu melalui BIPA (Bahasa Indonesia Bagi Penutur Asing), sebagaimana diungkapkan oleh Muliastuti bahwasanya internasionalisasi bahasa Indonesia yang ditingkatkan melalui pengajaran BIPA didukung oleh semua lembaga yang relevan. Pengajaran BIPA tidak hanya dilakukan di dalam negeri saja, tapi juga di luar Indonesia. Inilah yang pada akhirnya memberi dampak baik seperti jumlah penutur dan cakupan penggunaan bahasa Indonesia semakin bertambah ${ }^{3}$.

Perkembangan bahasa Indonesia bagi penutur asing (BIPA) di dunia internasional juga semakin melesat. BIPA tidak hanya diminati di kawasan ASEAN, tetapi juga di Asia dan Australia. Hal tersebut terbukti dengan adanya berita tentang peminatan bahasa Indonesia yang semakin tinggi di berbagai media. Selain di

\footnotetext{
1 Artikel-Jimat Susilo, "Internasionalisasi Bahasa Indonesia Melalui Program Pembelajaran BIPA Berbasis Budaya", tanpa tahun, 1

2 Jurnal-Febi Junaidi, "Implementasi Pembelajaran BIPA Berbasis Budaya sebagai Strategi Menghadapi MEA”, The $1^{\text {st }}$ Education and Language International Conference Proceedings Center for International Language of Unissula Mei 2017, 317

${ }^{3}$ Artikel-Liliana Muliastuti, "BIPA Pendukung Internasionalisasi Bahasa Indonesia”, 2016, 8
} 
kawasan ASEAN, Asia, dan Australia, BIPA juga sudah dijadikan mata kuliah di beberapa universitas di Eropa, salah satunya adalah di Finlandia. ${ }^{4}$

Selain diminati dan dilaksanakan di luar negeri, pembelajaran BIPA juga dilaksanakan di dalam negeri. Banyaknya pelajar asing yang menuntut ilmu di Indonesia membuat adanya pembelajaran BIPA di dalam negeri. Pada tahun 2012, tercatat lebih dari 45 lembaga telah mengajarkan bahasa Indonesia bagi penutur asing (BIPA), baik di perguruan tinggi maupun di lembaga-lembaga kursus. BIPA dapat diibaratkan seperti bayi yang baru lahir dan perlu didewasakan secara profesional dengan tanggung jawab keilmuan semua pihak. Karena itulah untuk memastikan bahwa BIPA dapat dikembangkan tidak hanya sistematis tapi sekaligus responsif terhadap keperluan pebelajar maka diperlukan telaah dan penataan yang seksama terhadap pola tutur esensial yang terdapat dalam Bahasa Indonesia ${ }^{5}$.

Dalam praktiknya, membelajarkan bahasa Indonesia kepada pembelajar asing memang harus secara tidak langsung disertai dengan memberikan pengetahuan tentang karakter atau identitas bangsa Indonesia. Sebagaimana pengajaran dalam BIPA yang tidak terlepas dengan karakter bangsa Indonesia yang majemuk dan kaya akan sumber daya alam dan kebudayaanya. Menurut Koentjaraningrat, terdapat aspek-aspek budaya yang bisa didayagunakan dalam menyampaikan materi ajar BIPA, yaitu (1) sistem peralatan serta perlengkapan hidup; (2) sistem mata pencarian hidup; (3) sistem; (4) bahasa; (5) kesenian; (6) sistem pengetahuan; dan (7) sistem religi. ${ }^{6}$

Pembelajaran BIPA berbasis budaya adalah salah satu cara yang bisa diterapkan kepada orang asing yang akan tinggal di Indonesia dalam waktu yang cukup lama. Dengan pembelajaran ini, tentu pebelajar asing akan sangat terbantu dalam meraih kompetensi dan standar penguasaan bahasa Indonesia yang dipersyaratkan. Selain itu, pembelajaran ini juga akan membekali pebelajar BIPA tentang keterampilan dalam berbahasa Indonesia dan pengetahuan tentang budaya Indonesia. Hal ini menjadi ranah yang penting untuk dilaksanakan untuk memberikan

\footnotetext{
${ }^{4}$ Jurnal-Sheilla Arumdyahsari dkk, Pengembangan Bahan Ajar Bahasa Indonesia Bagi Penutur Asing (BIPA) Tingkat Madya, jurnal pendidikan Vol 1 Nomor 5 Mei 2016, 828

5 Jurnal-Arisul Ulumuddin dan Agus Wismanto, Bahan Ajar Bahasa Indonesia Ranah Sosial Budaya Bagi Penutur Asing (BIPA), Jurnal Sasindo Vol 2 No. 1 Januari 2014, 6

6 Artikel-Abdul Gaffar Ruskhan, "Pemanfaatan Keberagaman Budaya Indonesia dalam Pengajaran Bahasa Indonesia bagi Penutur Asing (BIPA)" disajikan dalam Seminar Pengajaran Bahasa Indonesia di Jepang tahun 2007, 5
} 
pemahaman mengenai budaya Indonesia yang beraneka ragam, sehingga dapat membantu pebelajar BIPA dalam berinteraksi dan beradaptasi. Oleh sebab itu, isi pembelajaran BIPA sebaiknya mengandung nilai-nilai budaya Indonesia termasuk keunikannya. Pembelajaran BIPA tidak hanya bertujuan agar pebelajar menguasai bahasa verbal saja tapi juga konsep budaya serta adat istiadat di Indonesia yang juga menjadi komponen esensial untuk diketahui oleh pebelajar asing.

Melalui pembelajaran BIPA yang berbasis budaya, diharapkan akan memudahkan proses internasionalisasi bahasa dan budaya Indonesia, terutama di tingkat Asean. Pebelajar BIPA nantinya bisa mengenal bahasa dan budaya Indonesia dengan baik sehingga akan menjadi bekal mereka ketika menetap di Indonesia. Pembelajaran yang dirancang seperti itu tentu juga akan berkontribusi besar dalam mengenalkan dan memberikan pemahaman mengenai bahasa dan budaya Indonesia yang unik di mata dunia internasional. Dengan demikian, pebelajar BIPA tidak hanya memahami kaidah bahasa Indonesia saja tetapi juga bisa berkomunikasi dengan baik dan benar sesuai konteks bangsa Indonesia yang multikultural. Hal ini sangatlah penting, sebab konteks kultur di Indonesia dengan negara Asean lain tentunya terdapat perbedaan. ${ }^{7}$

\section{B. Metode Penelitian}

Metode yang digunakan dalam penelitian ini adalah library research, yang merupakan metode pengumpulan data dengan cara melakukan studi penelaahan terhadap buku, literatur, catatan dan laporan yang berkaitan dengan masalah yang dipecahkan. Sehingga menghasilkan data deskriptif mengenai "Internasionalisasi Bahasa Indonesia dan Internalisasi Budaya Indonesia Melalui Bahasa Indonesia Bagi Penutur Asing (BIPA)"

\section{Hasil dan Pembahasan}

\section{Urgensi Bahasa Indonesia di Dunia Internasional}

Era globalisasi ini merupakan tantangan bagi bangsa Indonesia untuk dapat mempertahankan diri di tengah-tengah pergaulan antarbangsa. Bangsa Indonesia harus menyiapkan diri dengan baik dan penuh perhitungan. Salah satu hal yang harus diperhatikan yaitu masalah identitas bangsa yang ditunjukkan melalui jati diri bahasa. Jati diri bahasa Indonesia adalah tata bahasanya yang

\footnotetext{
${ }^{7}$ Jurnal-Febi Junaidi, "Implementasi Pembelajaran BIPA Berbasis Budaya sebagai Strategi Menghadapi MEA", The $1^{\text {st }}$ Education and Language International Conference Proceedings Center for International Language of Unissula Mei 2017, 318
} 
simpel, mudah dipelajari, serta tidak terlalu rumit. Berkaitan dengan internasionalisasi bahasa Indonesia, pemerintah tidak boleh bergerak setengah hati dalam pengembangan dan pemertahanan bahasa Indonesia. Pemerintah memegang peranan yang cukup penting dalam merencanakan dan melaksanakan politik bahasa Indonesia ${ }^{8}$.

Sebagai pemilik bahasa Indonesia yang kita cintai, kita sangat berharap tingkat daya hidup bahasa Indonesia akan tetap aman, artinya bahasa Indonesia harus terus digunakan baik lisan maupun tulisan oleh semua generasi dan transmisi antar generasi tidak boleh terputus. Untuk memelihara agar bahasa Indonesia ada pada tingkat aman, maka kita sebagai penutur asli bahasa Indonesia tidak hanya selalu menggunakan bahasa Indonesia, namun sikap konsisten dan taat norma pun harus diperhatikan. Pada umumnya penutur bahasa Indonesia baru menunjukkan keberpihakan dan dukungan secara permukaan, belum menyentuh pada substansi atau orientasi penguasaan Bahasa Indonesia uang sesungguhnya. Menurut Asrini hakikat penguasaan bahasa Indonesia adalah membentuk penutur bahasa Indonesia dengan kualifikasi mampu berbahasa Indonesia untuk mengekspresikan gagasan atau idenya sesuai kaidah, cakap berbahasa Indonesia sesuai dengan kedudukan dan fungsinya, serta mampu menunjukkan sikap yang positif terhadap bahasa Indonesia. $^{9}$

\section{Bahasa Indonesia Bagi Penutur Asing (BIPA)}

BIPA adalah bentuk singkat dari Bahasa Indonesia untuk Penutur Asing. Sejalan dengan itu, program pengajaran BIPA adalah program pengajaran bahasa Indonesia khusus untuk penutur asing. Yang dimaksud dengan penutur asing di sini adalah penutur selain penutur bahasa Indonesia dan bahasa daerah (Inggris, China, Jerman, Jepang, Korea, Spanyol, dsb.). Tujuan dari program BIPA adalah agar si pembelajar dapat berkomunikasi dalam bahasa Indonesia secara wajar. Oleh karena itu, bahasa Indonesia adalah materi utama yang diajarkan kepada penutur asing di dalam program pengajaran BIPA $^{10}$.

\footnotetext{
${ }^{8}$ Buku-Mansur Muslich dan I gusti Ngurah Oka. "Perencanaan Bahasa pada Era Globalisasi”. Jakarta: PT. Bumi Aksara, 2010, 3

${ }^{9}$ Jurnal-Hari Windu Asrini, "Memperkokoh Kedudukan Bahasa Indonesia: Meneguhkan Sikap Positif Terhadap Bahasa Indonesia" dalam Prosiding Seminar Internasional. Universitas Muhammadiyah Malang, 4-5 November 2014, 6

${ }^{10}$ Jurnal-R. Panji Hermoyo Suher, "Pengembangan Materi Ajar BIPA Melalui Budaya Lokal Jawa Timur", Elementary School Education Journal Vol 1 Nomor 1 Agustus 2017, 49
} 
Pengajaran BIPA mempunyai karakteristik yang tidak sama. Salah satu yang membedakan yaitu dari segi pebelajarnya. Pebelajarnya BIPA adalah pebelajar yang sudah memiliki bahasa pertama (b1) dan memiliki latar belakang budaya yang berbeda. Selain itu, tujuan pebelajar BIPA juga sangat bermacammacam. Ada pelajar yang bertujuan hanya untuk belajar percakapan praktis saja, untuk mampu membaca, menulis, dan ada yang bertujuan untuk studi di Indonesia. Usia pebelajar yang bervariasi juga menjadi perhatian pada pembelajaran BIPA. Pendekatan yang digunakan oleh pengajar BIPA pada siswa asing berusia remaja jelas berbeda dengan yang berusia setengah baya. Perbedaan pendekatan ini pun berimbas pada metode, teknik, dan media yang digunakan.

Ada tiga fungsi strategis yang diemban oleh BIPA yaitu fungsi ilmiah akademis, sosial komunikatif dan strategis politis. Fungsi ilmiah akademis berkaitan dengan program pembelajaran bahasa Indonesia dimana para pembelajar (penutur-penutur asing baik yang ada di Indonesia ataupun di luar negeri) belajar bahasa Indonesia dari aspek linguistis (tata bahasa, kosa kata, ejaan, dan pelafalan). Dengan pembelajaran BIPA, penutur asing akan paham dan mengerti bagaimana struktur tata bahasa Indonesia yang benar, bagaimana melafalkan katakata dalam bahasa Indonesia dengan tepat, bagaimana cara menulis ejaan yang benar dalam tata bahasa Indonesia baku, menambah perbendaharaan kata bahasa Indonesia, dll. Hasil akhirnya adalah tercapainya kompetensi linguistik bahasa Indonesia oleh para penutur asing dan mereka dapat berkomunikasi dalam bahasa Indonesia secara wajar ${ }^{11}$.

Program BIPA semakin populer dan juga diminati sejak terbukanya perdagangan bebas. Tetapi sampai saat ini masih dijumpai perbedaan pendapat mengenai cara mengajarkan bahasa Indonesia kepada penutur asing yang efektif, baik berkaitan dengan alat-alat untuk mencapai tujuan, materi yang semestinya diajarkan, maupun metode pengajarannya. Sebab pada prakteknya banyak didapati variasi strategi dalam pembelajaran bahasa. Hal ini menunjukkan bahwa mengajarkan bahasa asing (termasuk bahasa Indonesia) tidak mudah dan perlu banyak pertimbangan.

Di Indonesia, program BIPA pun telah diselenggarakan di hampir semua perguruan tinggi ternama baik negeri maupun swasta. Sedangkan berdasarkan data

\footnotetext{
${ }^{11}$ Artikel-Arif Izzak, "Selayang Pandang BIPA Balai Bahasa Surabaya". Makalah disajikan pada Diskusi BIPA diselengarakan Universitas Muhammadiyah Surabaya, tanggal 9 September 2009.
} 
dari Pusat Bahasa di Jakarta, program pembelajaran BIPA telah dilaksanakan sekitar 46 negara di seluruh dunia, baik di lembaga perguruan tinggi maupun di kedutaan besar dan konsulat jenderal RI di berbagai negara. Sebagaimana beberapa informasi yang didapat dari berbagai fakta tentang keadaan dan perwujudan pembelajaran BIPA, munculnya BIPA adalah sejarah perkembangan bahasa Indonesia yang patut diabadikan terutama dalam penelitian. ${ }^{12}$

Berdasarkan kemampuannya pelajar BIPA terbagi menjadi tiga, yaitu tingkat pemula, tingkat menengah serta tingkat lanjut. Materi yang diberikan juga berbeda, disesuaikan dengan tingkatannya ${ }^{13}$. Hal tersebut sesuai dengan apa yang disampaikan oleh Suyitno bahwa materi bahasa dalam pembelajaran BIPA didasarkan pada tingkat kemampuan bahasa Indonesia pebelajarnya, misalnya untuk pengembangan materi membaca. Bagi tingkat pemula diberikan bacaan dalam bahasa Indonesia yang masih sederhana. Bacaan tersebut dapat diambil dari berbagai sumber seperti majalah anak, buku bahasa Indonesia SD, atau bacaan yang disusun oleh pengajar. Untuk tingkat menengah disuguhkan bacaan bahasa Indonesia yang lebih kompleks, dan bagi tingkat lanjut diberikan bacaan yang kompleks. Bacaan bagi pelajar tingkat menengah dan lanjut dapat diambil dari surat kabar ataupun majalah. Sedangkan pokok-pokok materi pengembangan budaya yang perlu diajarkan yaitu berkaitan dengan bagaimana hidup dalam keluarga, berteman, bermasyarakat, serta sopan santun dalam pergaulan. Tujuannya tidak lain adalah untuk menyiapkan pebelajar BIPA cakap berbahasa Indonesia sesuai dengan situasi dan kondisi. ${ }^{14}$

\section{Internalisasi Budaya Indonesia Melalui BIPA}

Era globalisasi yang semakin menjadi-jadi membuat berbagai aspek dalam kehidupan berlomba-lomba untuk menuju keadaan yang lebih baik lagi, salah satunya yaitu adanya proses internasionalisasi. Istilah internasionalisasi bisa jadi

\footnotetext{
${ }^{12}$ Artikel-Rifca Farih Azizah dkk, "Pembelajaran Bahasa Indonesia Bagi Penutur Asing (BIPA) Program CLS (Critical Language Scholarship) Di Fakultas Sastra Universitas Negeri Malang Tahun 2012”, 2012, 1

13 Jurnal-Rifqia Kartika Ningrum dkk, "BIPA (Bahasa Indonesia Penutur Asing) sebagai Upaya Internasionalisasi Universitas di Indonesia", The $1^{\text {st }}$ Education and Language International Conference Proceedings Center fot International Language Development of Unissula, Mei 2017, 728

14 Artikel-Imam Suyitno, "Norma Pedagogis dan Analisis Kebutuhan Belajar dalam Pembelajaran Bahasa Indonesia untuk Penutur Asing (BIPA)”, 2008, 68-69
} 
muncul karena dampak globalisasi. Hal tersebut dikarenakan proses internasionalisasi menuntut suatu hal tertentu untuk dapat dikenal dan diketahui oleh masyarakat global. Thoyib mengungkapkan bahwa internasionalisasi dalam konteks globalisasi pada dasarnya merupakan sebuah tanda kemajuan di bidang pendidikan. Internasionalisasi mampu menghadirkan harapan-harapan menuju ke arah yang lebih positif. Namun, di sisi lain internasionalisasi juga mampu membawa dampak buruk bagi yang tidak mampu mengelolanya dengan baik. ${ }^{15}$

Eksistensi bahasa Indonesia diharapkan tidak hanya dapat menjadi bahasa budaya tapi juga bahasa iptek yang berwibawa di antara dahsyatnya arus globalisasi. Sikap terbuka dan tidak kaku harus ditunjukkan dalam mengikuti kemajuan global. Masyarakat pun diharapkan setia dan bangga sebagai penutur dalam menggunakan bahasa Indonesia sebagai bahasa komunikasi dalam menghadapi masyarakat ekonomi ASEAN saat ini. Salah satu upayanya yaitu melalui pengajaran BIPA. ${ }^{16}$

Bahasa Indonesia sangat mungkin untuk dijadikan sebagai bahasa internasional karena bahasa Indonesia sangat mudah dipelajari dan dikuasai baik oleh penutur asli dan penutur asing. Seperti yang ditulis Subangu, beberapa potensi yang dimiliki bahasa Indonesia untuk menjadi bahasa internasional antara lain didukung oleh fakta-fakta sebagai berikut.

a. Bahasa Indonesia memiliki kesederhanaan struktur

b. Jumlah penutur

c. Luas penyebaran

d. Minat warga asing terhadap bahasa Indonesia

e. Penggunaan bahasa Indonesia di situs wordpress

Subangun juga menambahkan, meskipun peluang bahasa Indonesia menjadi bahasa internasional terbuka lebar, beberapa tantangan yang dihadapi juga sangat kompleks, yaitu sebagai berikut.

a. Rendahnya kemampuan bangsa Indonesia

b. Rendahnya sikap bangga berbahasa Indonesia

\footnotetext{
15 Jurnal-Thoyib, "Internasionalisasi Pendidikan dan Strategi Pengembangan Mutu Perguruan Tinggi Agama Islam di Indonesia: Sketsa Edukatif Manajemen Mutu”, Jurnal Pendidikan Islam El-Tarbawi, 1 (2) 2008,220

16 Artikel-Ngelu, Maria Santisima, "Eksistensi Bahasa Indonesia di Mata Dunia pada Era MEA". Makalah disajikan pada Seminar Nasional Pendidikan Bahasa Indonesia. Surakarta: Universitas Muhammadiyah Surakarta, 2015, 159
} 
c. Rendahnya daya tawar politik dan ekonomi ${ }^{17}$

Brown (dalam Supardo) menyatakan bahwa bahasa mempunyai hubungan yang erat dengan kebudayaan. Kebudayaan adalah bagian yang integral pada interaksi bahasa dan pikiran. Pola budaya, adat-istiadat, serta cara hidup manusia dinyatakan melalui bahasa. Pandangan dunia pun juga dinyatakan dalam bahasa. Hal ini sejalan dengan yang dikatakan oleh Chaer dan Agustina yang menyatakan bahwa hubungan antara bahasa dan kebudayaan adalah hubungan subordinatif, yang mana bahasa ada di bawah lingkup kebudayaan. Tetapi, ini bukanlah satusatunya konsep utama, karena terdapat pendapat lain yang mengatakan bahwa bahasa dan kebudayaan memiliki hubungan yang koordinatif, yaitu hubungan sederajat atau yang sama tingginya. ${ }^{18}$

Berdasarkan pendapat tersebut, dapat dipahami kalau bahasa mempunyai peran dalam kebudayan sebab pada dasarnya suatu kebudayaan akan diekspresikan melalui bahasa, terlepas dari pola hubungan keduanya. Seperti ketika membahaskan keadaan sebuah masyarakat, sebenarnya sebagian besar yang dibicarakan merupakan tentang budaya

Program pengajaran BIPA ini tidak hanya dirancang untuk program pengajaran bahasa Indonesia saja tetapi pebelajar diharapkan belajar budaya masyarakat Indonesia sehingga mereka bisa memahami bangsa Indonesia secara utuh. Dengan demikian tujuan utama program pengajaran BIPA adalah bukan untuk belajar tentang bahasa tetapi, lebih luas dari itu yaitu untuk belajar berbahasa dan memahami budaya masyarakat Indonesia. Pembelajaran BIPA pada dasarnya adalah pembelajaran berbahasa Indonesia pada non penutur asli bahasa Indonesia. Ini berarti berarti pembelajaran BIPA berada dalam wilayah pembelajaran bahasa kedua atau kesekian bagi pembelajarnya. ${ }^{19}$

Lestyarini berpendapat bahwa identitas kultural Indonesia sudah seharusnya disertakan dalam pembelajaran. Dengan mempelajari konteks budaya, kehidupan sosial masyarakat Indonesia, dan norma-norma sebagai nilai entitas masyarakat, penutur asing dapat mempelajari karakter Indonesia yang menjadi syarat mutlak yang harus dilakukan atau dikenal dengan istilah sine qua non untuk

\footnotetext{
${ }^{17}$ Jurnal-Subangun, "Peran Bahasa Indonesia sebagai Bahasa Ilmu Pengetahuan dan Bahasa Internasional dalam Membangun Peradaban Manusia" dalam Prosiding Seminar Internasional. Universitas Muhammadiyah Malang, 4-5 November 2014, 7-9

${ }^{18}$ Buku-A. Chaer dan Agustina L, "Sosiolinguistik Perkenalawan Awal”, Jakarta: PT Rineka Cipta, 2004,165

${ }^{19}$ Buku-Ari Kusmiatun, "Mengenal BIPA dan Pembelajarannya”, Yogyakarta: K-Media, 2015
} 
mempelajari bahasa Indonesia. Hal tersebut tentunya cukup untuk dimengerti karena bahasa merupakan salah satu cermin jati diri masyarakat sehingga kajian dan pembelajarannya tidak akan dapat pernah dilepaskan dari kehidupan masyarakat itu sendiri. ${ }^{20}$

Kemampuan berkomunikasi tidak hanya ditentukan dari pengetahuan tentang unsur kebahasaan, tapi juga pemahaman mengenai aspek budaya dalam masyarakat. Aspek budaya ini tentu sangat berperan dalam penggunaan bahasa. Oleh karena itu, agar dapat berkomunikasi secara baik dan benar, pebelajar bahasa diharapkan dapat memahami aspek-aspek budaya masyarakat yang bahasanya dipelajari. Bahasa merupakan representasi budaya yang mendeskripsikan budaya, termasuk di dalamnya pandangan dunia, kepercayaan, nilai, pengetahuan, dan pengalaman yang dianut komunitas bersangkutan.

Budaya sebagai salah satu materi yang penting, maka terdapat standar yang harus dikuasai oleh pebelajar BIPA. Selaras dengan itu Saddhono berpendapat bahwa culture aspects also became one of the five standards for foreign language mastery, including BIPA, in which the position can not be removed form four other standards. The five standards which must be gained by foreign language learners include: (1) communication, (2) culture, (3) connection, (4) comparison, and (5) communities. ${ }^{21}$ Maka dari itu materi-materi dalam BIPA harus sarat dengan budaya. Dalam memberikan materi bahasa Indonesia seharusnya aspek konteks budaya juga diberikan, karena dalam masyarakat terdapat ragam formal dan percakapan yang harus dipahami oleh mahasiswa asing sehingga tidak terjadi kesalahan pemakaian bahasa.

Sejalan dengan itu Andayani menjelaskan bahwa the introduction of local cultural treasures needs to be integrated in the teaching-learning process as well as assessment process, because local cultural treasures have close links with the language being studied. ${ }^{22}$ Oleh karena itu materi budaya dapat diintegrasikan dengan kegiatan ekskursi budaya. Hal ini akan memberikan motivasi kepada

\footnotetext{
${ }^{20}$ Artikel-Beniati Lestyarini, "Model Sintetik dan Analitik Berbasis Karakter Indonesia dalam Pembelajaran BIPA di Era Global", Makalah disajikan pada seminar Internasional ASILE 2012 dan KIPBIPA VIII LTCUKSW. Salatiga: Language Training Center Satya Wacana Christian University, 2012

${ }^{21}$ Jurnal-Kundharu Saddhono, "Integrating Culture in Indonesia Language Learning for Foreign Speakers at Indonesian Universities", Journal of Language Literature, 2015, 349

22 Jurnal-Gilang Lalita Andayani, "Improving the Language Skills and Local Cultural Understanding with Integrative Learning in Teaching Indonesian to Speakers of Other Language”, International Journal of Language and Linguistics 3(2) 2016, 45
} 
pembelajar BIPA untuk berani berinteraksi dan belajar budaya yang berbeda. Terutama memunculkan kebanggaan dan kecintaan terhadap bangsa Indonesia yang dipelajari. ${ }^{23}$

Melalui pemahaman budaya pebelajar bahasa dapat terhindar dari kemungkinan terjadinya benturan budaya (cultural shock) ketika berkomunikasi dengan penutur asli. Dengan kata lain, pemahaman aspek sosial budaya dapat berperan dalam menumbuhkan tata krama dalam diri pebelajar dalam berkomunikasi dengan penutur asli. Dalam perkuliahan bahasa (dalam hal ini BIPA), komponen budaya mempunyai peran yang penting. Pemahaman budaya yang tinggi dapat membantu penutur asing terhindar dari benturan budaya dengan penutur asli. Dengan begitu, komunikasi dapat berjalan efektif. Komponen sosial budaya dalam pembelajaran berbicara bahasa Indonesia untuk penutur asing meliputi:

a. Pengetahuan tentang kehidupan sosial dan budaya masyarakat di Indonesia

b. Kebudayaan/ ciri khas daerah-daerah di Indonesia

c. Sistem/norma yang ada di Indonesia, dan

d. Pariwisata dan kesenian daerah yang ada di Indonesia.

Komponen-komponen sosial budaya juga berisi tentang sejarah, letak, kebudayaan, agama, norma/peraturan yang berlaku di Indonesia. Setiap komponen sosial budaya bisa dijabarkan dalam tema-tema khusus yang menyinggung soalsoal pengembangan masyarakat Indonesia di berbagai bidang. ${ }^{24}$

\section{Penutup}

Bahasa Indonesia bukan tidak mungkin akan menjadi bahasa internasional. Jika dilihat dari eksistensinya saat ini, di mana bahasa Indonesia sudah mulai digunakan di banyak Negara. Bahkan dijadikan mata pelajaran wajib di sekolah dan menjadi bahasa kedua. Dengan demikian semua pihak, baik pemerintah hingga civitas akademika harus bersinergi bahu membahu saling mendukung untuk terwujudnya bahasa Indonesia yang dikenal oleh dunia.

\footnotetext{
${ }^{23}$ Jurnal-Ria Dwi Pusita Sari dkk, "Ekskursi Sebagai Strategi Belajar Bahasa Indonesia Bagi Penutur Asing (BIPA) dalam Masyarakat Ekonomi Asean (MEA)", The $1^{\text {st }}$ Education and Language International Conferencee Proceedings Center for International Development of Unissula, Mei 2017, 727

${ }^{24}$ Jurnal-Arisul Ulumuddin dan Agus Wismanto, "Bahan Ajar Bahasa Indonesia Ranah Sosial Budaya Bagi Penutur Asing (BIPA)”, Jurnal Sasindo Vol 2 No. 1 Januari 2014, 20
} 


\section{Daftar Pustaka}

Andayani, Gilang Lalita. 2016. Improving the Language Skills and Local Cultural Understanding with Integrative Learning in Teaching Indonesian to Speakers of Other Language. International Journal of Language and Linguistics 3(2).

Arumdyahsari, Sheilla dkk. 2016. Pengembangan Bahan Ajar Bahasa Indonesia Bagi Penutur Asing (BIPA) Tingkat Madya. Jurnal Pendidikan Vol 1 Nomor 5.

Asrini, Hari Windu. 2014. Memperkokoh Kedudukan Bahasa Indonesia: Meneguhkan Sikap Positif Terhadap Bahasa Indonesia dalam Prosiding Seminar Internasional. Universitas Muhammadiyah Malang.

Azizah, Rifca Farih dkk. 2012. Pembelajaran Bahasa Indonesia Bagi Penutur Asing (BIPA) Program CLS (Critical Language Scholarship) di Fakultas Sastra Universitas Negeri Malang Tahun 2012.

Chaer, A dan Agustina L. 2004. Sosiolinguistik Perkenalan Awal. Jakarta: PT Rineka Cipta

Izzak, Arif. 2009. Selayang Pandang BIPA Balai Bahasa Surabaya. Makalah disajikan pada Diskusi BIPA diselengarakan Universitas Muhammadiyah Surabaya.

Junaidi, Febi. 2017. Implementasi Pembelajaran BIPA Berbasis Budaya sebagai Strategi Menghadapi MEA. The $1^{\text {st }}$ Education and Language International Conference Proceedings Center for International Language of Unissula.

Kusmiatun, Ari. 2015. Mengenal BIPA dan Pembelajarannya. Yogyakarta: K-Media. Lestyarini, Beniati. (2012). Model Sintetik dan Analitik Berbasis Karakter Indonesia dalam Pembelajaran BIPA di Era Global. Makalah disajikan pada seminar Internasional ASILE 2012 dan KIPBIPA VIII LTC-UKSW. Salatiga: Language Training Center Satya Wacana Christian University.

Muliastuti, Liliana. 2016. BIPA Pendukung Internasionalisasi Bahasa Indonesia. Makalah disajikan pada seminar Nasional Politik Bahasa di Universitas Tidar Magelang. Magelang: Untidar.

Muslich, Masnur. dan I gusti Ngurah Oka. 2010. Perencanaan Bahasa pada Era Globalisasi. Jakarta: PT. Bumi Aksara.

Ningrum, Rifqia Kartika dkk. 2017. BIPA (Bahasa Indonesia Penutur Asing) sebagai Upaya Internasionalisasi Universitas di Indonesia, The $1^{\text {st }}$ Education and 
Dya Fatkhiyatur Rohimah

Language International Conference Proceedings Center fot International Language Development of Unissula.

Ngelu, Maria Santisima. 2015. Eksistensi Bahasa Indonesia di Mata Dunia pada Era MEA. Makalah disajikan pada Seminar Nasional Pendidikan Bahasa Indonesia. Surakarta: Universitas Muhammadiyah Surakarta.

Ruskhan, Abdul Gaffar. 2007. Pemanfaatan Keberagaman Budaya Indonesia dalam Pengajaran Bahasa Indonesia bagi Penutur Asing (BIPA). Makalah disajikan dalam Seminar Pengajaran Bahasa Indonesia Pertemuan Asosiasi JepangIndonesia di Nanzan Gakuen Training Center. Nagoya: Pusat Bahasa Departemen Pendidikan Nasional Republik Indonesia.

Saddhono, Kundharu. 2015. Integrating Culture in Indonesia Language Learning for Foreign Speakers at Indonesian Universities. Journal of Language Literature.

Sari, Ria Dwi Pusita dkk. 2017. Ekskursi Sebagai Strategi Belajar Bahasa Indonesia Bagi Penutur Asing (BIPA) dalam Masyarakat Ekonomi Asean (MEA), The $1^{\text {st }}$ Education and Language International Conferencee Proceedings Center for International Development of Unissula.

Subangun. 2014. Peran Bahasa Indonesia sebagai Bahasa Ilmu Pengetahuan dan Bahasa Internasional dalam Membangun Peradaban Manusia dalam Prosiding Seminar Internasional. Universitas Muhammadiyah Malang.

Suher, R. Panji Hermoyo. 2017. Pengembangan Materi Ajar BIPA Melalui Budaya Lokal Jawa Timur. Elementary School Education Journal Vol 1 Nomor 1

Susilo, Jimat. Tanpa Tahun. Internasionalisasi Bahasa Indonesia melalui Program Pembelajaran BIPA Berbasis Budaya.

Suyitno, Imam. (2008). Norma Pedagogis dan Analisis Kebutuhan Belajar dalam Pembelajaran Bahasa Indonesia untuk Penutur Asing (BIPA). Diksi, 15 (1), pp: 111-119.

Thoyib. 2008. Internasionalisasi Pendidikan dan Strategi Pengembangan Mutu Perguruan Tinggi Agama Islam di Indonesia: Sketsa Edukatif Manajemen Mutu. Jurnal Pendidikan Islam El-Tarbawi, 1 (2), pp. 215-234.

Ulumuddin, Arisul dan Agus Wismanto. 2014. Bahan Ajar Bahasa Indonesia Ranah Sosial Budaya Bagi Penutur Asing (BIPA). Jurnal Sasindo Vol 2 No. 1. 